\title{
On the Translation of Poetic Line Drawing from the Perspective of Transitivity
}

\author{
Qiqi Wang ${ }^{1} \&$ Jun Gao $^{1}$ \\ ${ }^{1}$ College of Foreign Languages, University of Shanghai for Science and Technology, Shanghai, China \\ Correspondence: Qiqi Wang, College of Foreign Languages, University of Shanghai for Science and Technology, \\ No. 516 Jungong Road., Shanghai 200093, China. E-mail: 297918213@qq.com
}

Received: June 30, 2021

Accepted: August 9, 2021

Online Published: August 18, 2021

doi:10.5539/ells.v11n3p77

URL: https://doi.org/10.5539/ells.v11n3p77

This research is sponsored by National Social Science Foundation, China. No.19BYY110.

\begin{abstract}
Poetic line drawing is a great challenge in translation since its simplicity and realism not only use the simplest words to concisely depict the fact but also enable readers to understand in numerous ways. Taking Tianjingsha.Qiusi as an example, this paper discusses the translation strategies of line drawing in poetry from the perspective of transitivity. By the comparison of three translations, it is found that line drawing can trigger multiple processes in the mental cognition of readers, and in most cases, different translators tend to maintain a certain process type and abandon others, which might lead to some loss of the poem's original charm and the translation turns out to be inaccurate. However, our study shows that such loss can be remedied through form equivalence strategy, for neither of the process types can be representative of all but only form equivalence can generate the same effect of the original poem.
\end{abstract}

Keywords: form equivalence, poetic line-drawing, transitivity

\section{Introduction}

Line drawing, originating from Chinese paintings, functions as a basis for the whole composition of the picture. That means employing repetition, continuity, contrastive difference of lines as well as various shades of ink to depict the profile of figures, the structure and texture of flowers and birds (Jiang, 2001). When it was introduced into the field of literature, line drawing was accordingly adjusted as an artistic technique that requires literary creators to stretch out the essence of the targeted object with limited linguistic symbols featuring realism and simplicity (Yu \& Xiang, 2018).

The current research on poetic line drawing mainly focuses on two parts. One concentrates on its origins and evolution (e.g., Jiang, 2001; Tan, 2003; Xu, 2014) while the other is interested in its application and appreciation (Yang \& Xu, 2011; Li, 2015; Chen \& Wang, 2021). But few are concerned about its translation from one language to another. Yu and Xiang (2018), based on Lu Xun's novels, analyzed translation strategies from the three perspectives of character description, narrative events, and scenery description. Since the translation of poetic line drawing that boasts Chinese characteristics weighs heavy in the cultural transmission, it is a great challenge to transfer such simplicity and realism to another language, while maintaining the original flavor.

\section{Literature Review}

As a masterpiece of Xiaoling (one of the tonal styles consisting of no more than fifty-eight characters) in the Yuan Dynasty, Tianjingsha.Qiusi goes with a line-drawing technique and outlines a picture of a quiet village at dusk in late autumn by listing nine sceneries. Brief and concise as Xiaoling, it creates a profound artistic conception and leaves readers a considerable imaginative space, empowering them to construct their mental reality. It is its flexibility that gives rise to the translating difficulty, for which several scholars have raised their own opinions. Huang (2003) raised the significance of formal equivalence in the poetry translation by the linguistic analysis of three translations of Tianjingsha.Qiusi. Huang (2004) emphasized the preservation of the cultural connotation when transferring the vital elements in this poem. Moreover, Wang (2009) believed the strategy of alienation enjoyed higher acceptance in terms of the readers' response. All mentioned above vary in distinctive views, putting forward enlightening opinions. However, the studies conducted from the perspective of 
functional grammar are very limited. Cheng and Liang (2008) held that changing the types of processes of the source text was likely to transform the meanings, so it is necessary to preserve the original processes as much as possible when translating (Cheng \& Liang, 2008). Xu and Tang (2020) also adopted a transitivity perspective in transferred epithet studies and translation and thought that transitivity is more perspective and explainable in revealing the relationship between syntactic structure and semantic structure of the figure of speech (Xu \& Tang, 2020). Therefore, it is of necessity to study from the perspective of transitivity. Wang (2011) had referred to transitivity but held the opposite view from the paper that the first sentence of Xiaoling didn't have processes. Thus, the paper aims to compare and analyze three translations of Tianjingsha.Qiusi by Xu Yuanchong, Ding Zuxin, and Schlepp from the perspective of transitivity to discuss how the types of processes are transferred during the translation and what effects might be achieved.

The three translations the paper employs are all typical. Two by remarkable translators as $\mathrm{Xu}$ Yuanchong and Ding Zuxin while the third one was translated by Schelpp, a famous poet who has received the doctor's degree with The Technique and Imagery of Yuan San-ch'u. In other words, Schelpp has a good command of Yuan songs.

\section{Theoretical Foundation}

Halliday (1994) puts forward three metafunctions: ideational function, interpersonal function, and textual function, among which ideational function can be further divided into experiential function and logical function. Experiential function refers to the construction of reality of the objective or subjective world through language, while transitivity refers to the presentation of this reality in various processes (material process, mental process, relational process, behavioral process, verbal process, existential process, etc.) (Halliday, 1994). In other words, transitivity can be viewed as a semantic system, which represents the experiential world in a series of processes. Material process refers to the process of doing something, including action, process, and goal; mental process refers to psychological activities such as thinking, feeling, and perception, which involves the sensor and the phenomenon; relational process refers to the relationship between two different entities, which is mainly classified into three types, namely, the intensive ( $\mathrm{x}$ is a), the circumstantial ( $\mathrm{x}$ is at a) and the possessive ( $\mathrm{x}$ has a), and two modes of attribute and identify. Behavioral process refers to physiological and psychological behaviors, such as coughing, smiling, breathing, etc., and generally refers to human beings; the verbal process is the process of saying; existential process refers to the process in which things exist or happen.

\section{Analysis of Poetic Line Drawing Translation from the Perspective of Transitivity}

\subsection{Analysis of the Transitivity of Tianjingsha Q Qiusi}

Xiaoling consists of two sentences with the first one containing three clauses and the second two clauses. Among them, the process analysis of the first clause is controversial. As mentioned above, Wang (2011) claimed that the language used in the poem lacked the description of details and did not involve any process (Wang, 2011), but the participating elements involved in the process may not necessarily appear, especially in the poetic language. More stress is put on the meaning instead of the form. The absence of some participating elements does not mean that the process does not exist.

Table 1. The processes of Tianjingsha.Qiusi

\begin{tabular}{|c|c|c|c|}
\hline 1 & $\begin{array}{l}\text { 枯藤老树昏鸦(rotten vines, } \\
\text { mental, relational, and existe }\end{array}$ & $\begin{array}{l}\text { evening crows) } \\
\text { esses }\end{array}$ & \\
\hline 2 & $\begin{array}{l}\text { 小桥流水人家(a small villa } \\
\text { mental, relational, and existe }\end{array}$ & $\begin{array}{l}\mathrm{m}, \text { a cottage) } \\
\text { esses }\end{array}$ & \\
\hline 3 & $\begin{array}{l}\text { 古道西风瘦马(ancient road } \\
\text { mental, relational, and existe }\end{array}$ & $\begin{array}{l}\text { wind, a lean horse) } \\
\text { esses }\end{array}$ & \\
\hline 4 material & $\begin{array}{l}\text { 夕阳(the sun) } \\
\text { Actor }\end{array}$ & $\begin{array}{l}\text { 西(westward) } \\
\text { Circumstance }\end{array}$ & $\begin{array}{l}\text { 下(goes down) } \\
\text { process }\end{array}$ \\
\hline 5 existential & $\begin{array}{l}\text { 断肠人(a heartbroken man) } \\
\text { existing object }\end{array}$ & $\begin{array}{l}\text { 在(is at) } \\
\text { existential verb }\end{array}$ & $\begin{array}{l}\text { 天涯(a place which is far from home) } \\
\text { circumstance }\end{array}$ \\
\hline
\end{tabular}

(1) In the sentence “枯藤老树昏鸦, 小桥流水人家, 古道西风瘦马”, there are nine sceneries without any verbs. That is, “枯藤(rotten vines)”, “老树(old trees)”, “昏鸦(evening crows)”, “小桥(the small bridge)”, “流水 (the stream)”, “人家(a cottage)”, “古道(the ancient road)”, “西风(the west wind)”, and “瘦马(a lean horse)”. Though with merely nine nouns, the charm of poetic line drawing lies in that it empowers people to understand in free and multiple ways. This line can be explained in the following ways. To start with, it can be a mental process that the author is the sensor, and what did he see is the phenomenon. But the author as the sensor did not 
appear in the line. Secondly, it can be considered as the attributive circumstantial relational process, in which the carrier is similar to the phenomenon in the mental process and the bleak and silent circumstance depicted by nine sceneries as an attribute. Lastly, it can be seen as an existential process that demonstrates the objective existence of these scenes. These different understandings, to great extent, are ascribed to the absence of the verb. That is, the implicit verb motivates readers to fill in the gap by themselves, resulting in a variety of the mental world. So it is hard to judge which one is correct and each reader has their preference. That's where the challenge of translation lies and the translators' diverse understandings are presented through their works as well.

(2) “夕阳西下, 断肠人在天涯” There are two processes in this sentence. The first clause can be viewed as the material process, where “夕阳(the sun)" is the actor, while “下(goes down)" is the process and “西(westward)" functions as the circumstantial component. The second clause can be interpreted in two ways: one is the attributive circumstantial relational process, in which the participants are “断肠人(a heartbroken man)" and “天 涯(a place which is far from home)", with “天涯” as the attribute and “断肠人” as the carrier. Another explanation is the existential process, where “在” is the verb indicative of existence, and “天涯” is the circumstantial element, while “断肠人” is the object existing in the scene. The existential verb “在” in the second clause makes the second clause more inclined to the interpretation of the existential process.

\subsection{Comparison of the Process Types of the Three Translations}

\subsubsection{Analysis of Xu's translation}

Table 2. The processes of Xu's translation

\begin{tabular}{llll}
\hline 1 material & Over old trees wreathed with rotten vines & fly & evening crows \\
& Circumstance & Process & actor \\
2 material & Under a small bridge near a cottage & a stream & flows \\
& Circumstance & Actor & process \\
3 material & On ancient road in the west wind & a lean horse & goes \\
& Circumstance & Actor & process \\
4 material & Westward & declines & the sun \\
& Circumstance & Process & actor \\
& Far, far from home & Is & the heartbroken one \\
& Attribute & Process circumstantial & carrier \\
& & &
\end{tabular}

As mentioned in the previous section, the first sentence of the poem can be interpreted as three processes. However, different translators may handle it in different ways. Like Xu's translation, he has transferred the line in a material process, with the addition of verbs as "fly, flows and goes", which are considered as processes. The objects of "rotten vines, old trees, a small bridge, a cottage, ancient road, the west wind" have been background as circumstantial components through the adoption of propositional phrases. Besides, "evening crows, a stream, a lean horse" have been translated as actors. Semantic relations among nine sceneries have become more explicit and been intensified in such material processes. For instance, nine objects in the source poem just simply juxtapose with each other but do not show what do they look like or how do they relate with each other. Nevertheless, in Xu's translation, "trees wreathed with rotten vines", "bridge near a cottage" and "road in the west wind" all stretch out what a whole picture looks like in detail.

The second line of the poem has been translated into two processes, the first of which is the material process, the same with the source one. "The sun" acts as the actor while "declines" works as the process and "westward" as the circumstantial element. The second clause is the attributive circumstantial relational process, in which the circumstance, "far, far from home" functions as an attribute and "the heartbroken man" as the carrier.

Therefore, it is not difficult to find that there are great changes in types of processes in Xu's translation that fixed the first line in the material type and the last clause into the relational process, describing more concretely and clearly than the source text. But at the same time, it limits readers' imagination to a certain mental image. 


\subsubsection{Analysis of Ding's Translation}

Table 3. The processes of Ding's translation

\begin{tabular}{|c|c|c|c|}
\hline 1 & $\begin{array}{l}\text { Withered vines hanging on old branches, } \\
\text { Returning crows croaking at dusk. } \\
\text { mental, relational, and existential processes }\end{array}$ & & \\
\hline 2 & $\begin{array}{l}\text { A few houses hidden past a narrow bridge, } \\
\text { And below the bridge a quiet creek running. } \\
\text { mental, relational, and existential processes }\end{array}$ & & \\
\hline 3 material & $\begin{array}{l}\text { Down a worn path, in the west wind, } \\
\text { Circumstance }\end{array}$ & $\begin{array}{l}\text { A lean horse } \\
\text { Actor }\end{array}$ & $\begin{array}{l}\text { comes plodding } \\
\text { process }\end{array}$ \\
\hline 4 material & $\begin{array}{l}\text { The sun } \\
\text { Actor }\end{array}$ & $\begin{array}{l}\text { dips down } \\
\text { process }\end{array}$ & $\begin{array}{l}\text { in the west } \\
\text { circumstance }\end{array}$ \\
\hline 5 relational & $\begin{array}{l}\text { And the lovesick traveler } \\
\text { Carrier }\end{array}$ & $\begin{array}{l}\text { is } \\
\text { Process circumstantial }\end{array}$ & $\begin{array}{l}\text { still at the end of the world. } \\
\text { attribute }\end{array}$ \\
\hline
\end{tabular}

Differing from Xu's, Ding's translation has reshaped the syntactic structure of Xiaoling, dividing the whole into four sentences. That is, three clauses of the first sentence in the original poem have developed into an independent sentence respectively which consists of other smaller clauses. Though they are sentences, the first two of them don't possess predicates. Verbs are present in the form of v-ing and v-ed, which means their processes are blurred. Similar to the source poem, they can be the mental, relational or existential process. But what makes difference is that the presence of v-ing and v-ed endows the line with the dynamic beauty. Besides, the third sentence in the target poem belongs to the material process, in which "a lean horse" is the actor, "comes plodding" is the process, and "down a worn path, in the west wind" is the circumstantial element. The last sentence, though employing different words, used the same type of process as Xu's that composes of the material process and the relational process, which can be referred to in detail in the above table.

To sum up, to some extent, Ding's translation has reproduced the feature of the poetic line drawing but his description also restrained the readers to a certain mental scene, like the use of "returning, croaking, plodding and so on", which do not appear in the source one. The merit is more description in detail can better present the author's emotions and feelings.

\subsubsection{Analysis of Schlepp's Translation}

Among the three translations, Schlepp's is the most particular since it has maintained the original structure of the poem, seeking formal equivalence as mentioned in Huang (2003) to keep Chinese cultural characteristics up to the most. The disparity is the last sentence of the target poem has inherited the trait of the first three clauses, paralleling two nouns, "the sun" and "one with breaking heart". Although "The sun declines westward", the material process has been changed, the verb "westering" still implies a dynamic moving process. One of poetic line drawing's features is the freedom it endows with the poetry. That Schlepp's translation utilized the strategy of alienation can well reserve it.

Table 4. The processes of Schlepp's translation

\begin{tabular}{|c|c|}
\hline 1 & $\begin{array}{l}\text { Dry vine, old tree, crow at dusk } \\
\text { mental, relational, and existential processes }\end{array}$ \\
\hline 2 & $\begin{array}{l}\text { Low bridge, stream running, cottages } \\
\text { mental, relational, and existential processes }\end{array}$ \\
\hline 3 & $\begin{array}{l}\text { Ancient road, west wind, lean nag } \\
\text { mental, relational, and existential processes }\end{array}$ \\
\hline 4 & $\begin{array}{l}\text { The sun westering } \\
\text { mental, relational, and existential processes }\end{array}$ \\
\hline 5 & $\begin{array}{l}\text { And one with breaking heart at the sky's edge } \\
\text { mental, relational, and existential processes }\end{array}$ \\
\hline
\end{tabular}

\subsection{Discussions}

From the above discussions, it is not difficult to find that poetic line drawing is too flexible to judge its process types. Its simplicity inevitably hides some information and leaves readers to add by themselves. That's also what 
makes the poem written by such language profound and linger on after reading and that's where the glistening point of Chinese poems is. So it is a tough task to demonstrate this feature when translating. What is analyzed above also proves that translators have their unique understanding and will adjust the translation accordingly. Indeed, Xu's and Ding's both added extra information which was absent in the source poem, making the information richer. Moreover, they translated the first sentence into different process types which vary from the original one. Nevertheless, the transformation of process types may contribute to the loss of accuracy. For example, poetic line drawing can trigger multiple processes, but when translated, it has been fixed into a certain process type, like in Xu's and Ding's translations, which fails to show Chinese poems' charm.

In contrast, Schlepp has followed the outline of the original poem and has tried to turn to formal equivalence to achieve functional equivalence. Thus, there is almost no change in the process types in the targeted work and even the translator has inherited and highlighted such structure in the last line of the poem to present the cultural connotation. It can be concluded that some artistic techniques like line-drawing are absent in English, so it inevitably leads to some loss of the original charm when translating, but an emphasis on forms, to some extent, can help make up such blank.

\section{Conclusion}

There are great differences between Chinese poems and English ones. Poetic line drawing as one of the Chinese-characteristic techniques is a key point to judge whether the translation of the poem is good or not. Nevertheless, owing to its variety of process types triggered, many translators may be puzzled about how to translate, and in most cases, they are likely to fix it to a certain process type during translation, which causes some loss of meaning and finally fails to boost readers to imagine and present the original charm. It seems that no matter which process is selected, there is a loss in meaning. However, by comparing the three translations, the study finds that it is helpful to represent the source poem's attractiveness through the reservation of the original form. In other words, formal equivalence in translating line drawing language in poetry can reduce the difficulty brought about by the simplicity of poetic line drawing since it reserves the original form, which to some extent also maintains its effects.

\section{References}

Chen, W., \& Wang, J.-Y. (2021). Line-drawing: Truth in News. News and Writing, 1, 105-107.

Cheng, X.-T., \& Liang, S.-W. (2008). Implications of the Transitivity Theory on Transformation in Translation. Foreign Languages and Their Teaching, 12, 42-45. https://doi.org/10.3969/j.issn.1004-6038.2008.12.010

Guan et al. (2018). 300 Yuan songs. Hohhot, CN: Yuanfang Publishing House.

Halliday, M. A. K. (1994). An introduction to functional grammar (2nd ed.). Edward Arnold, London.

Huang, G.-W. (2003). Formal Equivalence as a Criterion in Poetry Translation. Chinese Translators Journal, 24(2), 21-23.

Huang, X.-F. (2004). On the Cultural Connotations in the English Translation of Poems. Foreign Language Education, 25(2), 74-79. https://doi.org/10.3969/j.issn.1000-5544.2004.02.020

Jiang, X.-Y. (2001). Another Origin of Direct Lyric Expression a Theory Handed Down by History. Journal of South China Normal University (Social Science Edition), 3, 56-60. https://doi.org/10.3969/j.issn.1000-5455.2001.03.011

Li, X.-L. (2015). Wang Qiongling' s Hanxiao and Realism in Plain Description. Modern Chinese Literature Studies, 12, 95-101. https://doi.org/10.16287/j.cnki.cn11-2589/i.2015.12.009

Tan, G.-H. (2003). About the Theory of Origins of Uncluttered Writing. Journal of Zhangjiakou Teachers College, 19(4), 7-10. https://doi.org/10.3969/j.issn.1672-9951.2003.04.002

Wang, L.-L. (2011). An Analysis of Tianjingsha-Qiusi from the Perspective of Transitivity and Coherence. Masterpieces Review, 1, 47-48.

Wang, Q. (2009). An Analysis of the Better Approach on Translating Chinese Poetry in View of Readers' Responses-Taking Tune: Tian Jing Sha as an example. Journal of Nanchang University (Humanities and Social Sciences), 40(3), 152-154. https://doi.org/10.3969/j.issn.1006-0448.2009.03.030

Xu, L.-N., \& Tang, C.-M. (2020). A Transitivity Perspective on the Visual Neglect in Transferred Epithet Studies and Translation. Foreign Languages Research, 37(3), 67-73, 112. https://doi.org/10.13978/j.cnki.wyyj.2020.03.011

Xu, Z.-H. (2014). On Lu Xun's line-drawing theory. Journal of Shanxi University (Philosophy \& Social 
Science), 37(2), 131-136. https://doi.org/10.13451/j.cnki.shanxi.univ(phil.soc.).2014.02.015

Yang, Y., \& Xu, Y. (2011). Line-drawing and Contrastive Writing in the Narrative Tone of Zaoqiu. Masterpiece Review, 33, 62-63.

Yu, H. (2009). On the Notion of Genre Complex: Exploring the Logico-semantic Relations between Genres. Journal of PLA University of Foreign Languages, 32(2), 14-18, 28.

Yu, H., \& Xiang, D. (2018). Faithfulness vs. Effectiveness: Criteria for Translating Chinese Literature with Linguistic Distinction. Shanghai Journal of Translators, 2, 69-74, 95.

\section{Appendix A}

Three translations of Tianjingsha.Qiusi

Translation 1:

Tr. Wayne Schlepp

Tune to "Sand and Sky"

—Autumn Thoughts

Dry vine, old tree, crow at dusk

Low bridge, stream running, cottages

Ancient road, west wind, lean nag

The sun westering

And one with breaking heart at the sky's edge

Translation 2:

Ding Zuxin

To the Tune of Tianjingsha

Withered vines hanging on old branches,

Returning crows croaking at dusk.

A few houses hidden past a narrow bridge,

And below the bridge a quiet creek running.

Down a worn path, in the west wind,

A lean horse comes plodding.

The sun dips down in the west,

And the lovesick traveler is still at the end of the world.

Translation 3

$\mathrm{Xu}$ Yuanchong

Over old trees wreathed with rotten vines fly evening crows;

Under a small bridge near a cottage a stream flows;

On ancient road in the west wind a lean horse goes.

Westward declines the sun;

Far, far from home is the heartbroken one.

\section{Copyrights}

Copyright for this article is retained by the author, with first publication rights granted to the journal.

This is an open-access article distributed under the terms and conditions of the Creative Commons Attribution license (http://creativecommons.org/licenses/by/4.0/). 